\title{
EL PROCESO DE SEPARACIÓN CONVENCIONAL - NOTARIAL Y MUNICIPAL
}

\author{
Oscar Zegarra Guzmán*
}

\section{RESUMEN}

Luego de la dación en el año 2008 de la Ley que regula el procedimiento no contencioso de la separación convencional y divorcio ulterior en las municipalidades y notarias (Ley 29227), el transcurrir del tiempo nos ha demostrado que a pesar de representar la norma citada un avance en el tratamiento y pronta solución al problema de la separación convencional, también existen algunos factores y vacíos en la aplicación de lamisma, que aún no han sido corregidos.

Palabras claves: separación convencional, divorcio, procedimientono contencioso

\section{THE CONVENTIONAL-NOTARY MUNICIPAL SEPARATION PROCESS}

\section{ABSTRACT}

After the enactment in the year 2008 of the law which regulates the non-contentious procedure of the conventional separation and subsequent divorce in municipulities and notaries (Law 29227), the passing of time has shown us that despite the cited regulation represents a progress in the treatment and prompt solution to the problem of the conventional separation, there are also some factors and gaps in the application of separation that have not yet been corrected.

Key words: Conventional separation, divorce, non-contentious procedure.

\footnotetext{
* Abogado, con estudios de Maestría en la Pontificia Universidad Católica del Perú. Estudios de Derecho Bursátil en Lyon Francia y de Derecho Constitucional en Toledo, España. Fue Secxetario Académico en la Universidad de Lima. Dir zctor de Desarrollo Económico y Relaciones Internacionales en la Municipalidad de Bellavista, Callao. Gerente Legal del Municipio Provincial del Callao. Co-autor de la Ley General de Sociedades y de la Ley de Títulos Valores.
}

Recepción:03-08-2012

Aceptación: 28-08-2012 


\section{CUESTIONES PRELMINARES SOBRE EL PROCEDIMIENTO DE SEPARACIÓN CONVENCIONAL Y DIVORCIO ULTERIOR}

En el procedimiento de separación de convencional, tiene necesariamente que haber un acuerdo entre las partes en diferentes asunios, los cuales se manifiestan en la declaración de voluntad de las partes de separarse y en la formalidad de la presentación de una serie de documentos, a fin de poder tramitarse el pedido de separación convencional y posteriormente el divorcio. Esta ley tiene aproximadamente unos cuatro años y el resultado ha sido bastante eficiente. Eficiente por varias razones: porque la trama judicial es muy compleja, larga, tediosa y este dispositivo lo que busca - conforme lo señala la Ley y el Reglamento -, es agilizar la solución a una situación de hecho existente dentro de la sociedad peruana, de matrimonios rotos cuyos contrayentes ya tienen nuevas parejas y además una nueva conformación familiar, uniones que se han mantenido sólo en el papel, siendo el mecanismo regulado en la Ley No 29227 y su Reglamento, la opción que estaban esperando estas parejas a fin w evitar el engorroso y largo proceso judicial y acudir ante las Municipalidades o Notarías, en un procedimiento más ágil y rápido, sin que por esto deje de ser igualmente efectivo.

En una investigación sobre el tema se encontró que sólo alrededor de 800 municipalidades brindan este servicio de separación convencional y divorcio ulterior municipal a nivel nacional; las otras mil y tantas municipalidades - que son básicamente de provincia - no tienen idea que existe esta forma de divorcio o no la conocen. Además, debemos manifestar que su inclusión es un criterio opcional, ya que cada autoridad administrativa la incluye dentro de su listado de procedimientos administrativos o no, debiendo necesariamente obtener para ello, la autorización para realizar dicho trámite ante el Ministerio de Justicia.

Es entonces que queda a criterio de la autoridad administrativa, el adoptar dicho procedimiento, sabemos que el Ministerio de Justicia está tratando de fomentar que las Municipalidades lo hagan; sin embargo, ante la no inclusión por parte de la entidad, podría darse que si los vecinos lo exigen, puedan lograr que la Municipalidad lo incluya dentro de su TUPA.

Esta ley, sea del agrado de muchos o de pocos, regula una realidad social que ya comentamos. En su aplicación la Ley No 29227 regula el 
procedimiento señalando como supuesto de procedibilidad, que los solicitantes tienen que ser una pareja que se encuentre casada por un periodo no menor de 2 años, debiendo acreditar esto al órgano competente, con la partida de matrimonio, para poder ejercer esta posibilidad de declararse la separación convencional y el divorcio ulterior. De otro lado a fin de evitar discrepancias o conflictos al momento de iniciar el trámite o a la hora de la audiencia única, se debe haber definido los aspectos relacionados a los regímenes de alimentos, tenencia y de visitas. De igual modo, sierdo un procedimiento en el cual prima la voluntad de las partes, se deben adjuntar las declaraciones juradas del último domicilio conyugal, a fin de definir la competencia, por cuanto el trámite debe llevarse en la jurisdicción en la que se fijó el úl timo domicilio conyugal o donde se celebró el matrimonio, además la de no tener hijos menores ni mayores de edad con incapacidad, y de no tener bienes patrimoniales sujetos al régimen de sociedad de gananciales.

Es así que, veremos a dos autoridades (el alcalde y el notario) qiienes realizarán un acto vinculado al Derecho de Familia: el divorcio. Uno de ellos (el Alcalde) es elegido por el pueblo por 04 años o quizás por elecciones posteriores, pudiendo determinar bajo un buen criterio, si es que se aplica esta ley dentro de su jurisdicción. El otro, el Notario es el funcionario público reconocido, que está sujeto al régimen privado con carácter permanente, (durante el tiempo que le dure el ejercicio de su despacho notarial) está en condiciones de poder realizar el trámite del divorcio. Obviamente se debe considerar que si bien el procedimiento según la Ley y su reglamento es único, los costos son totalmente diferenciados.

Es en este estado, es decir ya en el desarrollo del procedimiento en sí, que la realidad diaria ha evidenciado la presencia de supuestos no contemplados por la Ley ni por su Reglamento, causando confusión y dudas en los operadores de la norma, haciendo por este hecho necesaria la aplicación supletoria de otras leyes y / o meditar en la posibilidad de la modificación de la propia Ley No 29227 y su Reglamento.

Veremos en este punto, algunos de estos supuestos no comprendidos en la norma. Este es el segundo tema a tratar. 


\section{LA APLICACIÓN DEL CÓDIGO CIVIL Y LA LEY DE PROCEDIMIENTO ADMINISTRATIVO GENERAL ANTE LOS VACÍOS EXISTENTES EN LA LEY N 29227 Y SU REGLAMENTO}

\section{La aparición de las figuras de la reconciliación, el desistimiento y la suspensión en el procedimiento de Separación Convencional y Divorcio Ulterior}

Partiendo del punto de vista que el procedimiento de separación convencional y divorcio ulterior es un procedimiento iniciado e impulsado por la voluntad de las partes, y siendo que esta voluntad persigue el término del vínculo matrimonial entre ambas, es que pueden darse, en el curso del mismo, algunos supuestos como el de la reconciliación, el desistimiento y la suspensión del procedimiento, figuras jurídicas que no se encuentran reguladas ni en la Ley $N^{\circ} 29227$ ni en su Reglamento.

Para los que en alguna oportunidad, ? mos sido operadores en este procedimiento, ha representado un reto la aplicación de la norma ante supuestos reales, que no se encuentran contemplados en ella.

\section{La reconciliación}

¿Qué hacer por ejemplo cuando iniciado el proceso de separación convencional las partes comunican que se ha producido la reconciliación entre ambas y que por ende ya no desean disolver su vínculo matrimonial?

Este supuesto no se encuentra comprendido en la norma ni en su Reglamento, pero es expresión de la voluntad de las partes, y un hecho que se puede presentar en el curso del procedimiento, en aras de mantener la unión familiar y porque priman los sentimientos que en su oportunidad los llevaron a contraer matrimonio.

En este caso ¿qué debemos hacer? el artículo $1^{\circ}$ de la Ley $\mathrm{N}^{\circ} 29227$ y el artículo $3^{\circ}$ de su Reglamento aprobado por el Decreto Supremo N$^{\circ}$ 009-2008JUS, señalan que para efectos de tramitar el procedimiento de separación convencional y divorcio ulterior, es necesaria la solicitud de ambos cónyuges después de transcurridos dos años de la celebración de su matrimonio. Es algo conocido por todos que este procedimiento ante Municipalidades y Notarías implica la voluntad de ambas partes de disolver 
el vínculo matrimonial, así como la no existencia de controversia o incertidumbre jurídica que resolver, en relación a los regímenes de tenencia, alimentos, de visitas y patrimonial.

¿Podremos continuar con el procedimiento si ambas partes han manifestado su voluntad de no continuar con el mismo por haberse producido la reconciliación entre ambos? Pues por supuesto que no, lo que debemos hacer aquí es declarar la conclusión del procedimiento por efecto de la manifestación de la voluntad de los cónyuges de persistir en su unión matrimonial.

¿Cuál es la norma aplicable? Pues habrá que remitirse a los alcances de lo previsto en el Código Civil, aplicando supletoriamente el título preliminar (artículo IX) del código sustantivo por razón de la materia.

\section{"Aplicación supletoria del Código Civil}

Artículo IX. - Las disposiciones del Código Civil se aplican supletoriamente a las relaciones y situaciones jurídicas reguladas por otras leyes, siempre que no sean incompatibles con su naturaleza".

De esta forma nos remitimos al artículo $346^{\circ}$ del Código Civil, que señala sobre la reconciliación de los cónyuges:

\section{"Efectos de la reconciliación de los cónyuges}

Artículo 346.- Cesan los efectos de la separación por la reconciliación de los cónyuges. Si la reconciliación se produce durante el juicio, el juez manda cortar el proceso. Si ocurriere después de la sentencia ejecutoriada, los cónyuges lo harán presente al juez dentro del mismo proceso.

Tanto la sentencia como la reconciliación producida después de ella se inscriben en el registro personal.

Reconciliados los cónyuges, puede demandarse nuevamente la separación sólo por causas nuevas o recién sabidas. En este juicio no se invocarán los hechos perdonados, sino en cuan to contribuyan a que el juez aprecie el valor de dichas causas".

En este estado hay que considerar asimismo lo contemplado en la Constitución de 1993, que señala en su artículo $4^{\circ}$ :

"Artículo $4^{\circ}$. La comunidad y el Estado protegen especialmente al niño, al adolescente, a la madre y al anciano en situación de abandono. Tombién protegen a la familia y promueven el matrimonio. Reconocen a estos últimos como institu tos naturales y fundamentales de la sociedad. 
La forma del matrimonio y las causas de separación y de disolución son reguladas porlaley".

Ante el supuesto enunciado hay que tener en consideración que, el Estado protege el matrimonio como una de las instituciones fundamentales de la sociedad, por lo que al presentarse el escrito en el que los cónyuges manifiestan que se han reconciliado, no queda más que aplicar supletoriamente el Código Civil y considerar que al no existir ya la voluntad de separarse y disolver el vínculo matrimonial por parte de los solicitantes, la entidad ya no debe seguir tramitando el procedimiento, por lo que debe declararlo CONCLUIDO por efecto de la reconciliación de los mismos.

\section{El Desistimiento}

También como operador de la norma se ha presentado el caso que, iniciado el trámite de separación convencional, el o los cónyuges se desisten del procedimiento. En este caso expresan por escrito los fundamentos que les han llevado a determinar su decisión, a fin de ser valorados por la administración y determinar el trámite a seguir. La pregunta es ¿bajo qué base legal? ¿El desistimiento de la pretensión o del proceso se encuentra regulado en la Ley No 29227 o en su Reglamento? Pues la respuesta es que tampoco ha sido considerado en la norma especial, por lo que en este extremo debemos considerar que, si bien es cierto la figura del desistimiento no es considerada en la Ley $N^{\circ} 29277$ ni en su Reglamento, la administración no puede dejar de adoptar las acciones correspondientes ante la voluntad expresa de los cónyuges, de renunciar al procedimiento de separación convencional.

Siendo de esta forma, al producirse la expresión de la voluntad de uno de los cónyuges, a fin de no continuar con el procedimiento y de dejar sin efecto su decisión inicial de separarse, es obligación de la administración tener en cuenta este hecho y pronunciarse en la debida medida.

En el caso de las Municipalidades, el procedimiento de separación de convencional y divorcio ulterior bajo los alcances de la Ley $\mathrm{N}^{\circ} 29227$ y su Reglamento D. S. No 009-2008-JUS, constituye uno de los procedimientos administrativos contemplados en el Texto Único de Procedimientos Administrativos de la entidad, ya que cada Municipalidad Provincial o Distrital, se encuentra facultada para su trámite, de conformidad a lo previsto por Resolución Directoral autoritativa del Ministerio de Justicia. Siendo así, consideramos que le son aplicables, de conformidad a la materia, las normas que regulan los procedimientos administrativos ante las entidades públicas, 
es decir la Ley No 27444 - Ley de Procedimiento Administrativo General, por cuanto el mismo no deja de ser un procedimiento administrativo en sí.

De esta forma, el artículo $189^{\circ}$ de la Ley $N^{\circ} 27444$ - Ley de Procedimiento Administrativo General, señala en sus numerales 189.4 y 189.5, que el desistimiento podrá hacerse por cualquier medio que perr vita su constancia y señalando su contenido y alcance. De igual forma puede realizarse en cualquier momento antes de que se notifique la resolución final en la instancia.

Bajo ese mismo entendimiento en los numerales 189.1 y 189.6 de la norma citada, se señala que el desistimiento del procedimiento importará la CULMINACIÓN del mismo, siendo que la autoridad aceptará de plano el desistimiento y declarará CONCLUIDO el procedimiento, salvo aue se perjudique intereses de terceros.

En este estado es que surge la interrogante: ¿qué sucede si se desiste sólo uno de los cónyuges? ¿y el derecho del otro cónyuge no es afectado por la decisión del desistimiento?. Sobre este último factor se puede apreciar que existen dos supuestos: a) el desistimiento de uno de los cónyuges y b) el de ambos cónyuges. En el primer supuesto, consideramos que la administración debe resolver de forma inmediata haciendo primar la voluntad de los cónyuges, es decir declarando CONCLUIDO el procedimiento por efecto del desistimiento realizado por los solicitantes. En el segundo supuesto, ante la afectación del derecho del otro cónyuge (que expresó su deseo de divorciarse), consideramos que puede aplicarse el numeral 189.6 de la norma citada, donde se precisa que habiéndose apersonado al proceso terceros interesados, deberán formular su opinión al respecto en el plazo de 10 días de notificados del desistimiento. En consideración a lo enunciado, debe trasladársele al otro cónyuge la solicitud a fin de que exprese su aceptación o no al desistimiento formulado. Ahora bien, es evidente que al no existir ya la voluntad de ambos cónyuges de seguir el procedimiento de separación convencional, mal haría la administración en continuar llevando el trámite, por lo que debe declararlo CONCLUIDO.

A manera de reflexión debo mencionar que desde nuestra experiencia en algunas municipalidades al presentarse los escritos que expresan la reconciliación o el desistimiento de los cónyuges y teniendo en cuenta que dichos supuestos no están contemplados en la norma, se comunica a los solicitantes la improcedencia de su pedido y se deja seguir el procedimiento hasta el momento de la audiencia, ya que si existe reconciliación de ambos o 
desistimiento de una o de las dos partes, se deberá recién dejar constancia de ello al momento de la audiencia. En caso de no acudir a la audiencia única recién por segunda vez, se declara CONCLUIDO el procedimiento, sin que se expresen como razones el desistimiento o reconciliación de los cónyuges, sino el hecho que él o los cónyuges no acudan en dos oportunidades a la audiencia, como lo señala el artículo $6^{\circ}$ de la Ley y $12^{\circ}$ del Reglamento. En este caso si bien es cierto, este es un mecanismo aceptable a fin de corroborar la voluntad de los cónyuges y suplir el vacío de la ley, consideramos que ya habiéndose expresado la voluntad de los cónyuges (cónyuge), era innecesario citar una vez y hasta dos veces a audiencia y recién entonces declarar concluido el proceso, ello sin perjuicio antes de haber notificado la improcedencia de la solicitud de los cónyuges, lo que claramente genera un accionar tedioso e innecesario por parte de la entidad.

\section{Suspensión del procedimiento}

En cuanto al tema de la suspensión del procedimiento, este es deducido por una o las dos partes en virtud a circunstancias de índole externo pero vinculadas a la solicitud, estas muchas veces son por discrepancias en cuanto al monto o porcentaje de los alimentos fijados, o también por factores de carácter patrimonial, (por ejemplo haber declarado no tener bienes patrimoniales cuando en realidad existe un bien inmueble que forma parte del patrimonio familiar), por lo que teniendo en cuenta que existen discrepancias en los aspectos que deben estar claramente definidos, según lo requiere la norma general, y recordando como ya hemos señalado, que la naturaleza de este procedimiento es el de ser no contencioso, es decir que no debe existir controversia ni discrepancia pendiente de resolver, por lo que el pedido de suspensión del procedimiento debe ser entendido más bien como de uno de conclusión del mismo, por cuanto ya no se cumplen las condiciones ni requerimientos de la norma a fin que se puede tramitar el procedimiento.

\section{SOBRE LOS ACTOS ADMINISTRATIVOS EMITIDOS EN EL PROCEDIMIENTO CUANDO SE PRESENTAN LOS SUPUESTOS DE RECONCILIACIÓN O DESISTIMIENTO O SUSPENSIÓN DEL PROCESO}

En este estado conviene realizarnos la siguiente pregunta: habiéndose presentado en el curso del procedimiento los pedidos de reconciliación, el desistimiento o la suspensión del procedimiento, como quedan los actos administrativos que se emitieron? 
Sobre este aspecto debemos remitirnos nuevamente a la Ley $\mathrm{N}^{\circ} 27444$, ya que este hecho tampoco se encuentra regulado en la norma especial, aplicando el numeral 203.2 del artículo $203^{\circ}$ de la norma citada, que establece la facultad de la administración de revocar los actos administrativos que haya emitido cuando sobrevenga la desaparición de las condiciones exigidas legalmente para la emisión del acto administrativo, las mismas que tienen la característica de ser indispensables para la existencia de la relación jurídica creada.

Juan Carlos Morón Urbina, en su libro Comentarios a la Ley del Procedimiento Administrativo General, señala que "tal como ha sido concebida la revocación en la Ley, resulta una facultad residual basada en norma expresa o un pacto previo al acto, mediante el cual se le priva de efectos no obstante ser un acto válido por razones de interés público. Así entendida, la revocación permíc a la administración, adaptarse constantemente a las necesidades del momento para su consonancia con el interés público".

Por la revocación se priva de efectos al acto administrativo emitido (es decir por ejemplo a la resolución que declara la separación convencional), ya que al haberse producido el desistimiento, la reconciliación de los cónyuges o la suspensión del procedimiento, se han desvirtuado los requisitos que dieron vida al acto administrativo, siendo de esta forma, el mismo ya no puede existir, por lo que debe ser revocado.

Después de haber analizado algunos aspectos referidos a la aplicación de la Ley No 29227 y su Reglamento, a manera de reflexión final nos permitimos sugerir que ya después de cuatro años de vigencia de la Ley, se hace necesaria una modificación de la misma, ya que como hemos manifestado largamente, la realidad ha superado a la Ley, y siendo que esta debe ser aplicada a supuestos reales, debe considerarse ya la opción de adecuarla convenientemente a los supuestos de hecho como los ya vistos, por cuanto como dijimos al principio, el uso de la norma constituye una solución al problema de las uniones mantenidas en papel, habiendose hasta ahora probado que siendo un procedimiento ágil y no engorroso, representa una opción más para quienes desean disolver su vinculo matrimonial sin tener que acudir al Poder Judicial para ello. 


\section{REFERENCIAS}

Código Civil Peruano - Decreto Legislativo 295, Diario Oficial El Peruano, Lima, Perú, publicado el 25 de julio de 1984.

Ley 29227, Diario Oficial El Peruano, Lima, Perú, publicado el 16 de mayo de 2008.

Reglamento D.S. No 009-2008-JUS, Diario Oficial El Peruano, Lima, Perú, publicado el 13 de junio de 2008.

Moron Urbina, Juan Carlos (2009) Comentarios a la Ley del Procedimiento Administrativo General. Lima: Edit Gaceta Jurídica". 